\title{
FAKTOR FAKTOR YANG MEMPENGARUHI KEPUASAN PELANGGAN SMARTPHONE SAMSUNG DI KOTA BATAM
}

\author{
Mohamad Gita Indrawan, Raymond, Dian Lestari Siregar \\ Universitas Batam , Indonesia \\ E-mail: mgitaindrawan@gmail.com
}

\begin{abstract}
Abstrak
This study aims to determine the effect of service quality and product promotion on customer satisfaction. This research was conducted by Samsung consumers in Batam in Batam City. The population in this study amounted to 135 people. In this research, the sampling technique used is classified as non - probability sampling technique with purposive sampling method. This study uses multiple linear regression analysis and has an R Square (R2) value in this study of 35.2\%. The results of the t-test in this study are the quality of service has a positive and significant effect on customer satisfaction and product promotion has a positive and significant effect on customer satisfaction. Based on the results of the F test in this study, the results showed that Service Quality and Product Promotion together had a positive and significant effect on Samsung Customer Satisfaction in Batam City.
\end{abstract}

Primarykey: Service Quality, Product Promotion, and Customer Satisfaction

\section{Pendahuluan}

Kepuasan pelanggan adalah respon atau reaksi terhadap ketidaksesuaian antara tingkat kepentingan sebelumnya dan kinerja aktual yang dirasakan setelah penggunaan atau pemakaian (Rangkuti, 2011: 31). Untuk dapat memenangkan persaingan dalam bisnis yang bergerak dalam bidang jasa, pelaku bisnis harus merencanakan strategi-strategi pemasaran untuk memuaskan keinginan pelanggan.

Kepuasan pelanggan terhadap perusahaan tidak terlepas dari faktor kualitas pelayanan yang diberikan dan promosi yang digunakan. Menurut (Tjiptono, 2011: 331) pada prinsipnya kualitas jasa (dalam hal ini adalah kualitas pelayanan) berfokus pada upaya pemenuhan kebutuhan dan keinginan pelanggan serta ketepatan penyampaiannya untuk mengimbangi harapan pelanggan. Dengan memberikan kualitas pelayanan yang baik akan memberikan suatu dorongan kepada pelanggan untuk menjalin ikatan kebutuhan yang kuat dengan perusahaan, Kualitas pelayanan yang baik mencangkup tangibles, Reliability, responsiveness, assurance, dan empathy (Tjiptono, 2011: 346-347). Kelima unsur kulitas pelayanan ini, paling tidak akan memberikan kepuasan pelanggan bila melayani melebihi harapan pelanggan. Pelayanan merupakan hal yang paling penting bagi perusahaan dalam melakukan strategi pemasaran ketika menjual produk yang sama. Pelayanan yang baik sering dinilai oleh pelanggan secara langsung dari karyawan sebagai orang yang melayani atau disebut juga sebagai produsen. Mengingat untuk mendapatkan pelanggan baru lebih besar biaya dibandingkan dengan pengorbanan dalam mempertahankan pelanggan lama. Karena itu diperlukan usaha perusahaan dalam meningkatkan kualitas pelayanan. Selain memberikan pelayan yang baik, perusahaan juga harus memberikan promosi produk agar terciptanya kepuasan pelanggan, Faktor lain yang mempengaruhi kepuasan pelanggan adalah promosi produk itu sendiri. (Sari, Mandey dan Soegoto, 2014: 1223) Pemasaran yang baik itu bukan kebetulan, melainkan hasil dari eksekusi dan perencanaan yang cermat. (Aprianto, 2016) Promosi merupakan cara bagaimana memperkenalkan produk kepada pelanggan dan calon pelanggan melalui periklanan, penjualan perorangan, promosi penjualan dan pemasaran langsung. Dengan dilakukan promosi, produk akan dikenal oleh pelanggan dan diharapkan pelanggan tertarik untuk memberli produk tersebut.

Samsung adalah salah satu jajaran smartphone yang dipasarkan oleh Samsung Electronics. Menurut manullang (2015) Pada saat ini permintaan masyarakat terhadap smartphone semakin 
meningkat, hal ini merupakan peluang bagi produsen handphone untuk menciptakan inovasi baru dalam pembuatan handphone yang dihasilkanya.

Saat ini banyak merek smartphone yang dipasarkan seperti Samsung, Oppo, Huawei, Xiaomi, Vivo, BlackBerry, Iphone, Nokia, Sony, Smartfreen, HTC, Lenovo, Realme, Mito, Advan, Asus, ZTE, Imo, dan lain sebagainya. Dari banyak pesaing tersebut berdasarkan analisis Canalys di kurtal keempat di tahun 2019 Samsung mengalami pertumbuhan tahunan paling rendah sebesar $1 \%$

Tabel 1 Pertumbuhan Penjualan Tahunan SmartPhone Tahun 2019

\begin{tabular}{|c|c|}
\hline Pemasok & Pertumbuhan Tahunan \\
\hline Apple & $+9 \%$ \\
\hline Samsung & $+1 \%$ \\
\hline Xiaomi & $+23 \%$ \\
\hline Oppo & $+2 \%$ \\
\hline
\end{tabular}

Berdasarkan data dari tabel 1 dapat dilihat bahwa tingkat penjualan tahunan smartphone Samsung pada tahun 2019 tumbuh sebesar 1 Persen terendah dibandingkan merek smartphone lainnya, hal ini berbeda dengan tingkat penjualan smartphone merek Xiaomi yang tumbuh sebesar $23 \%$, apple sebesar 9\% dan oppo sebesar 2\%. Rendahnya pertumbuhan penjualan Samsung tersebut diperkirakan dikarenakan kurangnya kualitas pelayanan yang diberikan dan kurangnya promosi produk sehingga mempengaruhi kepuasan pelanggan smartphone Samsung kHusunya yang terjadi Di Kota Batam, Untuk itu peneliti tertarik untuk melakukan verifikasi dan melakukan penelitian lebih dalam sehingga tujuan dari penelitian ini adalah untuk mengetahui faktor faktor yang mempengaruhi kepuasan pelanggan smartphone samsung di kota Batam.

Kualitas pelayanan berfokus pada upaya pemenuhan kebutuhan dan keinganan pelanggan serta ketepatan penyampaiannya untuk menyeimbangi harapan pelanggan (Tjiptono, 2014: 268). Promosi adalah salah satu bentuk komunikasi pemasaran, yang merupakan aktivitas pemasaran yang berusaha menyebarkan informasi, mempengaruhi/ membujuk, dan/ atau mengingatkan pasar sasaran atas perusahaan dan produknya agar bersedia menerima, membeli, dan loyal pada produk yang ditawarkan perusahaan yang bersangkutan (Hurriyati, 2017: 58). Kepuasan pelanggan adalah respon atau reaksi terhadap ketidaksesuaian antara tingkat kepentingan sebelumnya dan kinerja aktual yang dirasakan setelah penggunaan atau pemakaian (Rangkuti, 2011:31).

\section{MetodologiPenelitian}

\subsection{Desain penelitian}

Penelitian ini menggunakan desain penelitian secara deskriptif kuantitatif. Penelitian dilakukan dengan menguji kebenaran dari suatu hipotesis yang dilaksanakan melalui pengumpulan data di lapangan yang mengambil sampel dari suatu populasi penelitian ini menggunakan metode survey penelitian ini menggunakan metode statisik regresi berganda.

Alat dalam penelitian ini menggunakan aplikasi SPPS Version 21 dengan pengumpulan data berupa kuesioner, dan kuesioner yang digunakan adalah kuesioner tertutup. Kuesioner merupakan teknik pengumpulan data yang dilakukan dengan cara memberi seperangkat pertanyaan atau pernyataan tertulis kepada responden untuk dijawabnya. Kuesioner dalam penelitan ini berisi pernyataan mengenai data penelitian Kualitas Pelayanan dan Promosi Produk terhadap Kepuasan Pelanggan smartphone samsung di kota Batam.

\subsection{Populasi dan sampel}

Populasi dalam penelitian ini adalah pelanggan smartphone Samsung di Kota Batam. Penelitian ini menggunakan teknik sampel yang diambil oleh peneliti menggunakan teknik non prohability sampling yaitu salah satu pengambilan sampel secara sengaja dengan pertimbangan tertentu dari peneliti. Metode penarikan sampel ditentukan dengan menggunakan rumus Slovin dengan tingkat kesalahan 5\% (Noor, 2011: 158) sehingga sampel dalam penelitian sebanyak 135 responden 


\subsection{Teknik pengujian Instrumen}

\subsubsection{Uji Validititas}

Uji validitas digunakan untuk mengukur sah atau valid tidaknya suatu kuesioner. Suatu kuesioner dikatakan valid jika pernyataan kuesioner mampu mengungkapkan sesuatu yang akan diukur oleh kuesioner tersebut (Ghozali, 2011: 52). Kriteria pengujiannya adalah nilai $r$ dibandingkan dengan nilai $r$ tabel dengan derajat bebas ( $n-2)$. Jika nilai $r$ hasil perhitungan lebih besar daripada nilai $r$ dalam tabel pada alfa tertentu maka berarti signifikan sehingga disimpulkan bahwa butir pertanyaan atau pernyataan itu valid (Sanusi, 2014: 77).

\subsubsection{Uji Reliabilitas}

Reliabilitas adalah alat untuk mengukur suatu kuesioner yang merupakan indikator dari variabel atau konstruk. Suatu kuesioner dikatakan reliabel atau handal jika jawaban seseorang terhadap pernyataan adalah sejalan atau stabil dari waktu ke waktu (Ghozali, 2011: 47). Pengujian reliabilitas instrumen dalam penelitian ini dilakukan dengan teknik Cronbach's Alpha dimana suatu instrumen dapat dikatakan handal (reliabel) apabila memiliki koefisien kehandalan/Alpha > 0,6. Apabila nilai Alpha $<0,6$ maka instrumen dikatakan tidak reliabel.

\subsection{Uji Asumsi Klasik}

\subsubsection{Uji Normalitas Data}

Uji normalitas bertujuan untuk menguji apakah dalam model regresi, variabel pengganggu atau residual memiliki distribusi normal.

\subsubsection{Uji Multikolonieritas}

Uji multikoliniearitas bertujuan untuk menguji apakah model regresi ditemukan adanya korelasi antara variabel bebas (independen). Model regresi yang baik sebaiknya tidak terjadi korelasi di antara variabel independen (Ghozali, 2011: 105)

\subsubsection{Uji Heteroskedastisitas}

Uji Heterokedastisitas bertujuan untuk menguji apakah dalam model regresi terjadi ketidaksamaan variandan residual satu pengamatan ke pengamatan lain. Jika varian dari residual satu pengamatan ke pengamatan lain tetap disebut sebagai homoskedastisitas dan jika berbeda disebut sebagai heteroskedastisitas (Ghozali, 2011: 139).

\subsubsection{Uji Hipotesis}

\subsubsection{Uji t}

Uji t merupakan uji yang digunakan untuk mengetahui apakah variabel independen secara parsial berpengaruh terhadap variabel dependen (Priyatno, 2013: 120). Kriteria penerimaan atau penolakan hipotesis dalam penelitian ini adalah: Jika $t$ hitung $>\mathrm{t}$ tabel dan nilai signifikan $<0,05$, maka hipotesis pertama dan kedua dalam penelitian ini diterima dan jikat hitung $\leq \mathrm{t}$ tabel dan signifikan $\geq 0,05$, maka hipotesis pertama dan kedua dalam penelitian ini ditolak.

\subsubsection{Uji F}

Uji statistik F pada dasarnya menunjukkan apakah semua variabel independen atau bebas yang dimasukkan dalam model mempunyai pengaruh secara bersama-sama terhadap variabel dependen atau terikat (Ghozali, 2011: 98). 


\section{Hasil dan Pembahasan}

\subsection{Uji validitas}

Tabel 4.1. Uji Validitas

\begin{tabular}{ccccc}
\hline Variabel & Pernyataan & r hitung & r tabel & Keterangan \\
\hline \multirow{4}{*}{ Kualitas Pelayanan } & X1_1 & 0,653 & 0,1690 & Valid \\
(X1) & X1_2 & 0,727 & 0,1690 & Valid \\
& X1_3 & 0,764 & 0,1690 & Valid \\
& X1_4 & 0,845 & 0,1690 & Valid \\
& X1_5 & 0,809 & 0,1690 & Valid \\
Promosi Produk & X2_1 & 0,819 & 0,1690 & Valid \\
(X2) & X2_2 & 0,519 & 0,1690 & Valid \\
& X2_4 & 0,763 & 0,1690 & Valid \\
Kepuasan Pelanggan & X2_5 & 0,811 & 0,1690 & Valid \\
(Y) & Y_1 & 0,808 & 0,1690 & Valid \\
& Y_2 & 0,786 & 0,1690 & Valid \\
& Y_3 & 0,896 & 0,1690 & Valid \\
& Y_4 & 0,841 & 0,1690 & Valid \\
\hline
\end{tabular}

Dari tabel 4.1 dapat disimpulkan bahwa variabel Kualitas Pelayanan (X1), Promosi Produk (X2) dan Kepuasan Pelanggan (Y) dinyatakan valid karena $r$ hitung lebih besar dari $r$ tabel.

\subsection{Uji Reabilitas}

Tabel 4.2. Uji Reabilitas

\begin{tabular}{ccccc}
\hline No. & Variabel & Cronbach's alpha & Standar & Keterangan \\
\hline 1 & Kualitas Pelayanan (X1) & 0,817 & 0,6 & Reliabel \\
2 & Promosi Produk (X2) & 0,795 & 0,6 & Reliabel \\
3 & Kepuasan Pelanggan (Y) & 0,793 & 0,6 & Reliabel \\
\hline
\end{tabular}

Dari tabel 4. 2 disimpulkan bahwa variabel Kualitas Pelayanan (X1), Promosi Produk (X2) dan Kepuasan Pelanggan (Y) memiliki nilai Cronbach's alpha > 0,6 artinya setiap variabel dinyatakan reliabel

\subsection{Uji Normalitas}

Tabel 4.3. Uji Normalitas

\begin{tabular}{lcr}
\hline \multicolumn{2}{c}{ One Sample Kolmogorov Smirnov Test } \\
\hline & & Unstandardized Residual \\
$\mathrm{N}$ & & 109 \\
Normal Parameters & &, 0000000 \\
& Sean & 1,56828915 \\
Most Extreme Differences & Absolute &, 051 \\
& Positive &, 038 \\
& Negative &,- 051 \\
Kolomograv Smirnov Z & &, 531 \\
Asymp. Sig. (2-tailed) & &, 940 \\
\hline
\end{tabular}

Berdasarkan tabel 4.3 diketahui bahwa nilai signifikansi (Asym.Sig.2-tailed) sebesar 0,940. Karena nilai Asymp.Sig lebih besar dari 0,05 maka distribusi data adalah normal. Maka dapat disimpulkan bahwa data sudah berdistribusi normal 


\subsection{Uji Multikolinearitas}

Tabel 4.4. Uji Multikolinearitas

\begin{tabular}{lcc}
\hline \multicolumn{1}{c}{ Model } & \multicolumn{2}{c}{ Collinearity Statistics } \\
& Tolerance & VIF \\
\hline Total_X1 (Kualitas Pelayanan) &, 973 & 1,028 \\
Total_X2 (Promosi Produk) &, 973 & 1,028 \\
\hline
\end{tabular}

Berdasarkan tabel 4.4 hasil uji multikolinearitas diketahui bahwa nilai VIF pada variabel X1 (Kualitas Pelayanan) dan varibel X2 (Promosi Produk) sebesar 1,028 kurang dari 10 dan Tolerance sebesar 0,404 lebih besar dari 0,1.Maka dapat disimpulkan bahwa model regresi tidak terjadi masalah multikolonieritas.

\subsection{Uji Heteroskedastisitas}

Tabel 4.5. Uji heteroskedastisitas

\begin{tabular}{|c|c|c|c|c|c|}
\hline \multirow[t]{2}{*}{ Model } & \multicolumn{2}{|c|}{$\begin{array}{l}\text { Unstandardized } \\
\text { Coefficients }\end{array}$} & \multirow{2}{*}{$\begin{array}{c}\text { Standardized } \\
\text { Coefficients } \\
\text { Beta } \\
\end{array}$} & \multirow[t]{2}{*}{$\mathrm{t}$} & \multirow[t]{2}{*}{ Sig. } \\
\hline & B & Std. Error & & & \\
\hline (Constant) &, 636 & 1,001 & &, 635 &, 526 \\
\hline Total_X1 &, 017 &, 039 & 039 & 441 & 660 \\
\hline Total_X2 &, 026 &, 040 &, 058 & 661 &, 510 \\
\hline
\end{tabular}

Berdasarkan tabel 5 nilai probabilitas atau signifikansi masing-masing variabel adalah sebesar 0,660 dan 0,510. Maka dapat disimpulkan bahwa model regresi tidak terdapat gejala heteroskedastistitas

\subsection{Uji t}

Tabel 4.6. Uji $\mathrm{T}$

\begin{tabular}{|c|c|c|c|c|c|c|}
\hline & \multirow[t]{2}{*}{ Model } & \multicolumn{2}{|c|}{$\begin{array}{l}\text { Unstandardized } \\
\text { Coefficients }\end{array}$} & \multirow{2}{*}{$\begin{array}{c}\text { Standardized } \\
\text { Coefficients } \\
\text { Beta } \\
\end{array}$} & \multirow[t]{2}{*}{$\mathrm{t}$} & \multirow[t]{2}{*}{ Sig. } \\
\hline & & B & Std. Error & & & \\
\hline \multirow{3}{*}{1} & (Constant) & 3,827 & 1,540 & & 2,485 & 014 \\
\hline & Total_X1 &, 460 &, 060 &, 545 & 7,674 &, 000 \\
\hline & Total_X2 & , 141 &, 062 &, 162 & 2,282 & ,024 \\
\hline
\end{tabular}

Berdasarkan hasil pada tabel 4.6. diperoleh t hitung atas variabel X1 (Kualitas Pelayanan) sebesar positif 7,674 dan t hitung variabel X2 (Promosi Produk) sebesar positif 2,282. Variabel Kualitas Pelayanan berpengaruh positif dan signifikan terhadap Kepuasan Pelanggan. Dikatakan positif karena nilai t hitung untuk variabel Kualitas Pelayanan adalah positif sebesar 7,647. Maka dapat disimpulkan bahwa hipotesis pertama dalam penelitian ini diterima. Variabel Promosi Produk berpengaruh positif dan signifikan terhadap Kepuasan Pelanggan. Dikatakan signifikan karena nilai signifikan dari variabel Promosi produk sebesar 0,024 lebih kecil dari nilai $\alpha 0,05$. Maka dapat disimpulkan bahwa hipotesis kedua dalam penelitian ini diterima.

\subsection{Uji F}

Tabel 4.7. Uji F

\begin{tabular}{llccccc}
\hline \multicolumn{1}{c}{ Model } & Sum of Square & df & Mean Square & F & Sig. \\
\hline & Regression & 282,503 & 2 & 141,251 & 35,919 &, $000^{6}$ \\
1 & Residual & 519,097 & 132 & 3,933 & & \\
Total & 801,600 & 134 & & &
\end{tabular}

Uji statistik $\mathrm{F}$ tabel dapat dicari pada tabel statistik dengan menggunakan tingkat keyakinan $95 \%, \alpha=5 \%$, df $1(k-1)$ dimana $\mathrm{k}$ adalah jumlah variabel sehingga dihitung $\mathrm{df} 1=(3-1)=2 \mathrm{dan} \mathrm{df}$ 
2 (n-k) dimana $\mathrm{n}$ adalah jumlah populasi sehingga df $2=(135-3)=132$. Maka diperoleh nilai $\mathrm{F}$ tabel $=3,06$. Pada tabel 9 diperoleh hasil bahwa variabel Kualitas Pelayanan dan Promosi Produk secara bersama-sama berpengaruh positif dan signifikan terhadap Kepuasan Pelanggan. Hasil F hitung sebesar positif 35,919 dan nilai signifikan 0,000 lebih kecil dari nilai $\alpha$ 0,05. Maka dapat disimpulkan bahwa hipotesis ketiga dalam penelitian ini diterima

\section{Kesimpulan}

Berdasarkan hasil analisis dan pembahasan yang telah dipaparkan pada bab sebelumnya, maka dapat diambil kesimpulan sebagai berikut:

1. Kualitas Pelayanan berpengaruh positif dan signifikan terhadap Kepuasan Pelanggan.

2. Promosi Produk berpengaruh positif dan signifikan terhadap Kepuasan Pelanggan.

3. Kualitas Pelayanan dan Promosi Produk secara bersama-sama berpengaruh positif dan signifikan terhadap Kepuasan Pelanggan.

Saran untuk penelitian ini ialah sebagai berikut :

1. Pihak Samsung diharapkan lebih memfokuskan kepuasan pelanggan dengan memperhatikan keluhan-keluhan pelanggan.

2. Pihak Samsung diharapkan dapat meningkatkan kualitas pelayanan terhadap pelanggan agar terciptannya kepuasan pelanggan.

\section{Daftar Pustaka}

[1] Aprianto, R. (2016). Pengaruh Promosi dan Pelayanan terhadap Kepuasan Pelanggan pada Toko BNJ Elektronik Kota Lubuklinggau. Buletin Bisnis \& Manajemen, 02(01), 41-63.

[2] Christian, R. P., \& Lisbeth Mananeke. (2016). Pengaruh Strategi Promosi dan Kualitas Layanan Terhadap Kepuasan Pelanggan Pengguna BPJS di RSUD Sam Ratulangi Tondano. Jurnal EMBA, 4(2), 121-132.

[3] Dewa, C. B. (2018). Pengaruh Kualitas Pelayanan dan Promosi Penjualan Jasa Grabcar Terhadap Kepuasan Pelanggan (Studi Kasus Pada Wisatawan di Yogyakarta). Perspektif, 16(1), 1-6.

[4] Faradina, A. (2016). Pengaruh Promosi dan Kualitas Pelayanan Terhadap Kepuasan Pelanggan pada Rumah Cantik Almanda. Jurnal Ilmu Dan Riset Manajemen, 5(7), 1-18.

[5] Ghozali, I. (2011). Aplikasi Analisis Multivariat dengan Program IBM SPSS 19 (5th ed.). Semarang: Badan Penerbit UNDIP.

[6] Gulla, R., Oroh, S. G., \& Roring, F. (2015). Analisis Harga, Promosi, Dan Kualitas Pelayanan Terhadap Kepuasan Konsumen Pada Hotel Manado Grace Inn. Jurnal EMBA, 3(1), 1313-1323.

[7] Handoko, B. (2017). Pengaruh Promosi, Harga Dan Kualitas Pelayanan Terhadap Kepuasan Konsumen Pada Titipan Kilat JNE Medan. Jurnal Ilmiah Manajemen \& Bisnis, 18(1), 61-72.

[8] Hurriyati, R. (2017). Bauran Pemasaran dan Loyalitas Konsumen (4th ed.). Bandung: Alfabeta.

[9] Kadhim, D. F. A., Abdullah, T. F., \& Abdullah, M. F. (2016). Effects Of Marketing Mix On customer Satisfaction: Empirical Study On Tourism industry In Malaysia. International Journal of Applied Research, 2(2), 357-360.

[10] Manampiring, A. S., Tumbuan, W. J. A. ., \& Wenas, R. S. (2016). Analisis Produk, Harga, Lokasi, Promosi Terhadap Kepuasan Konsumen pada Kartu Kredit PT Bank Mandiri TBK. Manado. Jurnal EMBA, 4(2), 164-176.

[11] Noor, J. (2011). Metodologi Penelitian. Jakarta: Prenada Media Group.

[12] Rangkuti, F. (2011). Riset Pemasaran. Jakarta: Gramedia Pustaka Utama. 
[13] Rasmansyah. (2017). The effect of service quality and promotion to customer satisfaction and implication of customer loyalty in vehicle financing company in Jakarta Indonesia. International Journal of Advanced Scentific Research, 2(6), 22-30.

[14] Sanusi, A. (2014). Metodologi Penelitian Bisnis (4th ed.). Jakarta: Salemba Empat.

[15] Sugiyono. (2012). Metode Penelitian Bisnis. Bandung: Alfabeta.

[16] Sugiyono, \& Susanto, A. (2015). Cara Mudah Belajar SPSS dan Lisrel. Bandung: Alfabeta.

[17] Tjiptono, F. (2014). Pemasaran Jasa. Yogyakarta: Andi Offset.

[18] Tjiptono, F., \& Chandra, G. (2016). Service, Quality and Satisfaction (4th ed.). Yogyakarta: Andi Offset.

[19] Yamit, Z. (2013). Manajemen Kualitas Produk dan Jasa. Yogyakarta: Ekonisia.

[20] Yanuar, M. M., Nurul, Q., \& Budi, S. (2017). Dampak kualitas produk, harga, promosi dan kualitas pelayanan terhadap kepuasan pelanggan optik marlin cabang jember. Jurnal Manajemen Dan Bisnis Indonesia, 3(1), 61-80. 